\title{
Synthesis of Single-Crystalline Niobate Nanorods via lon-Exchange Based on Molten-Salt Reaction
}

\author{
Cheng-Yan Xu, ${ }^{\dagger, \ddagger}$ Liang Zhen, ${ }^{\star, \dagger}$ Rusen Yang, ${ }^{\ddagger}$ and Zhong Lin Wang ${ }^{\star, \ddagger}$ \\ School of Materials Science and Engineering, Harbin Institute of Technology, Harbin 150001, China, and School of \\ Materials Science and Engineering, Georgia Institute of Technology, Atlanta, Georgia 30332
}

Received September 18, 2007; E-mail: Izhen@hit.edu.cn; zhong.wang@mse.gatech.edu

One-dimensional (1D) nanostructures of ternary complex oxides have drawn intensive interest because of their novel size-dependent properties, such as ferroelectric, ${ }^{1 \mathrm{a}}$ multiferroic, ${ }^{\mathrm{lb}}$ and superconductivity. ${ }^{1 c}$ Various synthetic approaches, such as aqueous route by employing hydrothermal reaction ${ }^{2}$ or templates, ${ }^{3}$ molten-salt synthesis, ${ }^{4}$ and composite-hydroxide-mediated synthesis ${ }^{5}$ have been developed for the synthesis of different kinds of ternary metal oxides 1D nanostructures, for example, alkali titanates, ${ }^{6}$ peroskite-type ferroelectric titanates, ${ }^{7,4 c}$ vanadates, ${ }^{8}$ niobates, ${ }^{9}$ and $\mathrm{ABO}_{4}$-type chromates and tungstates. ${ }^{10}$

Alkali and alkali earth niobates might exhibit excellent nonlinear optical and dielectric properties, on the basis of which novel nanodevices might be designed by utilizing their 1D nanostructures. For example, subwavelength optical microscopy by employing tunable nanometric light source based on $\mathrm{KNbO}_{3}$ nanowires were developed by Yang and co-workers. ${ }^{11}$ Despite the attractive applications of niobates, there are only a few reports on the synthesis of niobate 1D nanostructures by employing the hydrothermal approach. ${ }^{9}$ In this Communication, we have developed a facile ionexchange approach for the synthesis of single-crystal sodium and calcium niobates nanorods based on molten-salt reaction between $\mathrm{K}_{2} \mathrm{Nb}_{8} \mathrm{O}_{21}$ nanowires and molten sodium or calcium salts. The proposed synthetic route is suggested to be a self-sacrificing templated process. The starting template of $\mathrm{K}_{2} \mathrm{Nb}_{8} \mathrm{O}_{21}$ nanowires was prepared by calcinations of $\mathrm{Nb}_{2} \mathrm{O}_{5}$ in molten potassium chloride, similar to our previous report on the synthesis of $\mathrm{K}_{2} \mathrm{Nb}_{8} \mathrm{O}_{21}$ nanoribbons. ${ }^{12}$ Although previously ion-exchange has already been explored for the synthesis of titanate nanowires, ${ }^{13}$ these works were mainly based on an aqueous solution reaction, which is timeconsuming and thus not suitable for large-scale synthesis. The proposed ion-exchange approach based on molten-salt synthesis is thus attractive for its rapid and large-scale fabrication of 1D nanostructures of ternary complex oxides.

The synthesis of sodium and calcium niobate nanorods is a twostep process. First, $\mathrm{K}_{2} \mathrm{Nb}_{8} \mathrm{O}_{21}$ nanowires were prepared by calcination of $\mathrm{Nb}_{2} \mathrm{O}_{5}$ powders in molten $\mathrm{KCl}$ at $1000{ }^{\circ} \mathrm{C}$ for $3 \mathrm{~h}$. Then, the mixture of $\mathrm{K}_{2} \mathrm{Nb}_{8} \mathrm{O}_{21}$ nanowires and $\mathrm{NaCl}$ (or $\mathrm{CaCl}_{2}$ ) was heated in a tube furnace at 825 or $800{ }^{\circ} \mathrm{C}$ for $3 \mathrm{~h}$ and allowed to cool naturally to room temperature. The resulting powders were washed several times with distilled water and then dried at room temperature.

Figure 1a shows the X-ray diffraction (XRD) pattern of the assynthesized potassium niobate nanowires. All of the diffraction peaks can be assigned to the orthorhombic phase of $\mathrm{K}_{2} \mathrm{Nb}_{8} \mathrm{O}_{21}$ (JCPDS 31-1098) with lattice parameters of $a=3.75, b=1.25$, and $c=0.396 \mathrm{~nm},{ }^{14}$ indicating pure phase of the product. The morphology of the synthesized niobate nanowires was examined by scanning electron microscopy (SEM), as shown in Figure $1 \mathrm{~b}$.

$\dagger$ Harbin Institute of Technology.

¥ Georgia Institute of Technology.

15444 a J. AM. CHEM. SOC. 2007, 129, 15444-15445
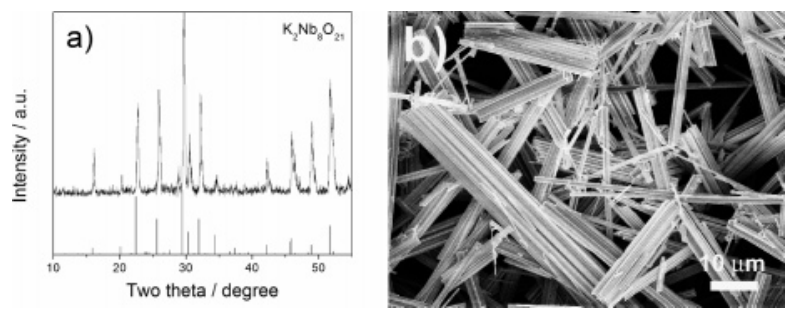

Figure 1. (a) XRD and (b) SEM image of potassium niobate nanowires. The angles for the standard sample of potassium niobate are shown at the lower part of panel a.

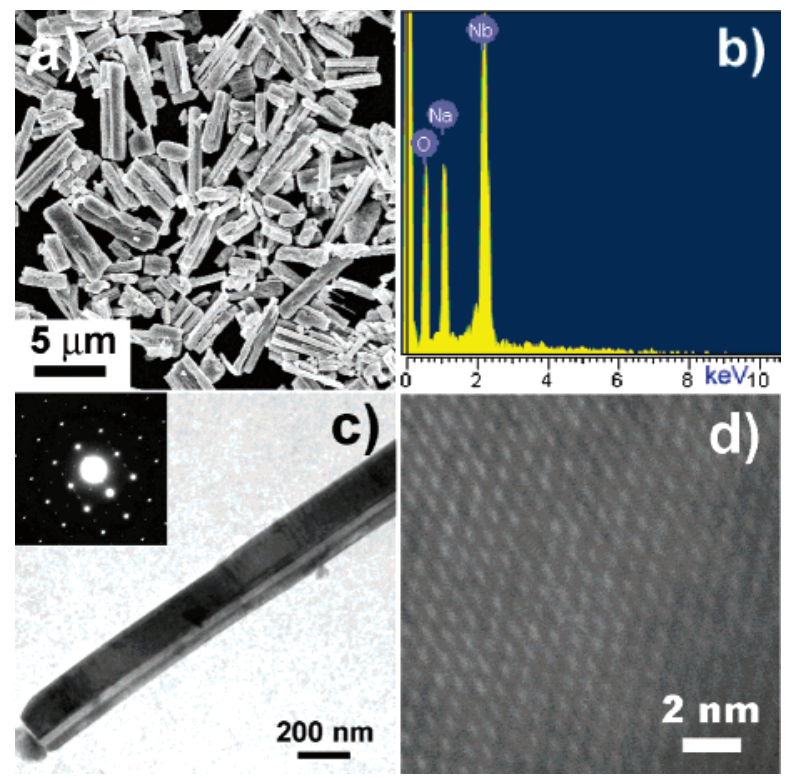

Figure 2. (a) SEM image of sodium niobate nanorods. (b) EDX spectrum showing the complete conversion from $\mathrm{K}$ niobate to Na niobate. (c) TEM image of an individual sodium niobate nanorod. Inset is the corresponding SAED pattern. (d) High-resolution TEM image of the same nanorod shown in panel $\mathrm{c}$.

A large quantity of nanowires with diameters of several hundred nanometers was observed. The length of nanowires can reach up to several tens of micrometers, and most nanowires tend to form bundles (Figure S1). Selected area electron diffraction (SAED) patterns taken from a wealth of nanowires indicate that they are single-crystalline in nature. The growth direction of the synthesized $\mathrm{K}_{2} \mathrm{Nb}_{8} \mathrm{O}_{21}$ nanowires was determined to be its [001] crystallographic direction (Figure S2).

A large scale of sodium niobate nanorods was obtained via an ion-exchange reaction between $\mathrm{K}_{2} \mathrm{Nb}_{8} \mathrm{O}_{21}$ nanowires and molten $\mathrm{NaCl}$ salt, as shown in Figure 2a. The synthesized sodium niobate nanorods, with the same diameters of a few hundred nanowires as that of the precursor, and lengths of several micrometers, show 


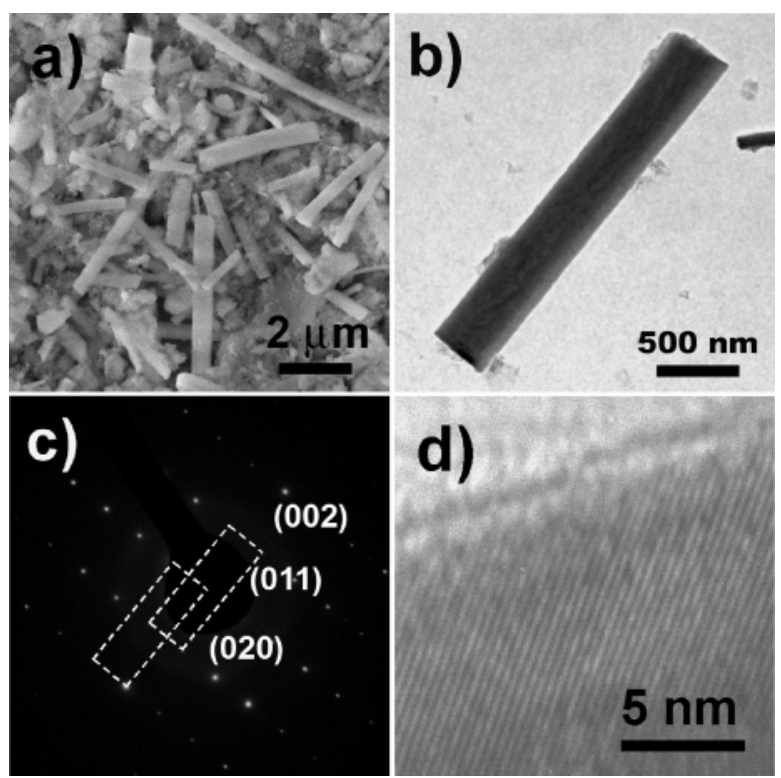

Figure 3. (a) SEM image of calcium niobate nanorods. (b) TEM image of an individual calcium niobate nanorod and (c) its corresponding SAED pattern and (d) HRTEM image.

bundlelike morphology, which is the characteristic of the starting template of $\mathrm{K}_{2} \mathrm{Nb}_{8} \mathrm{O}_{21}$ nanowires. The phase of the obtained sodium niobate was determined to be orthorhombic $\mathrm{NaNbO}_{3}$ (JCPDS $33-$ 1270, Figure S3), with lattice parameters of $a=0.5569, b=1.5123$, and $c=0.5505 \mathrm{~nm}$. Energy dispersive X-ray spectroscopy (EDS) (Figure $3 b$ ) indicates the compete conversion from potassium niobate to sodium niobate. The SAED pattern (Figure 2c inset) taken from the nanorod shown in Figure 2c depicts clearly the singlecrystalline nature of the obtained sodium niobate nanorods via ionexchange, which is further proved by HRTEM image of the same nanorod (Figure 2d). The growth direction of $\mathrm{NaNbO}_{3}$ nanorods was determined to be along [101].

It is expected that other niobate 1D nanostructures can be also obtained by utilizing this template-assisted method via ion-exchange based on molten-salt reaction. A mixture of potassium niobate nanowires and $\mathrm{CaCl}_{2}$ was heated at $800{ }^{\circ} \mathrm{C}$ for $3 \mathrm{~h}$, and calcium niobate nanorods with diameters of a few hundreds of nanometers and lengths of several micrometers were obtained (Figure 3a). The phase of the obtained calcium niobate was determined to be orthorhombic $\mathrm{CaNb}_{2} \mathrm{O}_{6}$ (JCPDS 39-1392, Figure S4), with lattice parameters of $a=0.5748, b=1.4987$, and $c=0.5226 \mathrm{~nm}$. The EDX spectrum (Figure S5) indicates that potassium ions can be also completely displaced by calcium ones to form phase-pure calcium niobate nanorods. The obtained calcium niobate nanorods were confirmed to be also single-crystalline, as shown in Figure $3 b$ and $3 c$, in which the growth direction is the [001]. HRTEM image shown in Figure $3 \mathrm{~d}$ further demonstrates the single-crystalline nature of the obtained calcium niobate nanorods.

The synthesis of sodium and calcium niobate nanorods via ionexchange was thought to be a self-sacrificing templated process..$^{15}$ The 1D growth of sodium niobate nanorods was not due to its intrinsic growth habit. Calcining of $\mathrm{Nb}_{2} \mathrm{O}_{5}$ powders in molten $\mathrm{NaCl}$ leads to the formation of the same phase of $\mathrm{NaNbO}_{3}$ particles, but not in 1D form (Figure S6). The bundlelike morphology of sodium niobate nanorods (Figure S7) further confirms the self-sacrificing templated growth behavior. The smaller ion radius of sodium and calcium compared with potassium ion allow the exchange of sodium or calcium ions and potassium ion during the molten-salt reaction, and the high temperature and molten-salt environment were thought to benefit the formation of single-crystalline nanorods. The difference between the two kinds of ions might be the reason for the formation of nanorods but not nanowires. We further examine the product of ion-exchange reaction between $\mathrm{K}_{2} \mathrm{Nb}_{8} \mathrm{O}_{21}$ nanowires and molten $\mathrm{LiCl} . \mathrm{LiNbO}_{3}$ nanoparticles but not nanorods (Figure S8, S9) were obtained, indicating that the difference between two kinds of ions is vital in determination of the morphology of final products. The wirelike nanoparticle-assembles shown in Figure S10 offer further evidence of self-sacrificing templated growth behavior during ion-exchange.

In summary, we have demonstrated an ion-exchange approach based on molten-salt reaction for the synthesis of single-crystalline niobate $1 \mathrm{D}$ nanostructures. $\mathrm{NaNbO}_{3}$ and $\mathrm{CaNb}_{2} \mathrm{O}_{6}$ nanorods can be prepared via the simple ion-exchange reaction from $\mathrm{K}_{2} \mathrm{Nb}_{8} \mathrm{O}_{21}$ nanowires. The synthesis process was postulated to be a selfsacrificing templated process. This method may also be extended to the fabrication of other ternary oxide 1D nanostructures.

Acknowledgment. C. Y. Xu was supported by the Development Program for Outstanding Young Teachers and Internationalization Foundation of HIT.

Supporting Information Available: SEM, TEM, HRTEM images and SAED pattern of $\mathrm{K}_{2} \mathrm{Nb}_{8} \mathrm{O}_{21}$ nanowires, XRD pattern and EDS of sodium and calcium niobates nanorods, and XRD pattern and SEM images of $\mathrm{LiNbO}_{3}$ particles. This material is available free of charge via the Internet at http://pubs.acs.org.

\section{References}

(1) (a) Yun, W. S.; Urban, J. J.; Gu, Q.; Park, H. Nano Lett. 2002, 2, 447.(b) Park T. J.; Mao Y. B.; Wong S. S. Chem. Commun. 2004, 2708 (c) Zhang, Y. F.; Tang, Y. H.; Duan, X. F.; Zhang, Y.; Lee, C. S.; Wang, N.; Bello, I.; Lee, S. T. Chem. Phys. Lett. 2000, 323, 180.

(2) Sun, X.; Chen, X.; Li, Y. D. Inorg. Chem. 2004, 41, 4996.

(3) Mao, Y. B.; Wong, S. S. J. Am. Chem. Soc. 2004, 126, 15245.

(4) (a) Mao, Y. B.; Banerjee, S.; Wong, S. S. J. Am. Chem. Soc. 2003, 125 15718. (b) Xu, C. Y.; Zhang, Q.; Zhang, H.; Zhen, L.; Tang, J.; Qin, L.-C. J. Am. Chem. Soc. 2005, 127, 11584. (c) Cai, Z. Y.; Xing, X. R.; $\mathrm{Yu}, \mathrm{R} . \mathrm{B}$.; Li, G. R. Inorg. Chem. 2007, 46, 7423.

(5) Liu, H.; Hu, C. G.; Wang, Z. L. Nano Lett. 2006, 6, 1535.

(6) (a) Yuan, Z. L.; Su, B. L. Colloids Surf., A 2004, 241, 183.(b) Chen Q.; Zhou W. Z.; Du G. H.; Peng L. M.; Adv. Mater. 2002, 14, 1208 (c) Du G. H.; Chen Q.; Han P. D.; Yu Y.; Peng L. M.; Phys. Rev. B 2003, 67, 035323 .

(7) (a) Urban, J. J.; Yun, W. S.; Gu, Q.; Park, H. J. Am. Chem. Soc. 2002 124, 1186. (b) Joshi U. A.; Lee J. S.; Small 2005, 1, 1172.

(8) (a) Yu, J. G.; Yu, J. C.; Ho, W.; Wu, L.; Wang, X. C. J. Am. Chem. Soc. 2004, 126, 3422. (b) Mao, C. J.; Wu, X. C.; Pan, H. C.; Zhu, J. J.; Chen, H. Y. Nanotechnology 2005, 16, 2892.

(9) (a) Liu, J. F.; Li, X. L.; Li, Y. D. J. Cryst. Growth 2003, 247, 419. (b) Magrez, A.; Vasco, E.; Seo, J. W.; Dieker, C.; Setter, N.; Forro, L. J. Phys. Chem. B 2006, 110, 58.

(10) (a) Shi, H. T.; Qi, L. M.; Ma, J. M.; Cheng, H. M. J. Am. Chem. Soc. 2003, 125, 3450. (b) Liang, J. H.; Peng, C.; Wang, X.; Zheng, X.; Wang, R. J.; Qiu, X. P.; Nan, C. W.; Li, Y. D. Inorg. Chem. 2005, 44, 9405. (c) Wang, W. S.; Xu, C. Y.; Zhen, L.; Yang, L.; Shao, W. Z. Chem. Lett. 2006, 35, 268

(11) Nakayama, Y.; Pauzauskie, P. J.; Radenovic, A.; Onorato, R. M.; Saykally, R. J.; Liphardt, J.; Yang, P. Nature 2007, 447, 1098.

(12) Xu C. Y.; Zhen L.; Yang L.; He K.; Shao W. Z.; Qin L.-C. Ceram. Int $\mathbf{2 0 0 8}, 34$, in press.

(13) Wang, R. H.; Chen, Q.; Wang, B. L.; Zhang, S.; Peng, L. M. Appl. Phys. Lett. 2005, 86, 133101.

(14) Teng C. M.; Li F. H.; Yang D. Y.; Wu Q. Z. J. Chinese Ceram. Soc 1986, 4, 484 (in Chinese).

(15) See, for example, Yang B. J.; Mo. M. S.; Hu H. M.; Li C.; Yang X. G.; Li Q. W.; Qian Y. T. Europ. J. Inorg. Chem. 2004, 1785.

JA077251T 